\title{
THE IMPACT OF WIND-POWER GENERATION ON THE PLANNING OF REGULATING RESERVE
}

\author{
Dunja Srpak, Boštjan Polajžer
}

Original scientific paper

This paper presents new approach to the optimal distribution of the regulating reserve (RR) in a set of available regulating generation units. It is developed using evolutionary computation for the transmission-loss minimization and power-flow computation by applying the iterative method with a reactive power correction for voltage control. The approach involves the use of actual operating data directly from the network's dispatch centre as well as daily and hourly plans of wind and load power for determining the RR requirements for the load frequency control (LFC). By testing the proposed approach on a case study, the possibility of implementing it on real power systems is demonstrated. The obtained results of the testing with actual data from the Croatian control area indicate substantial savings in ancillary service costs for the LFC and the considerable impact of different variations from the plan of each individual wind-power plant on the optimal RR distribution.

Keywords: evolutionary computation; frequency control; optimization; power system; regulating reserve; wind power generation

Utjecaj proizvodnje iz vjetroelektrana na planiranje regulacijskih rezervi

Izvorni znanstveni članak Ovaj članak predstavlja novi pristup za određivanje optimalne raspodjele regulacijskih rezervi (RR) između raspoloživih regulacijskih proizvodnih jedinica. Razvijen je korištenjem evolucijskog algoritma za minimiziranje gubitaka prijenosa i proračuna tokova snaga iterativnom metodom sa korekcijom reaktivne snage za regulaciju napona. Ovaj pristup uključuje uporabu stvarnih operativnih podataka izravno iz dispečerskog centra, kao i dnevne i satne planove potrošnje i proizvodnje iz vjetroelektrana za utvrđivanje potrebne snage za regulaciju frekvencije. Testiranjem predloženog pristupa na studiji slučaja, pokazana je mogućnost primjene na realnim elektroenergetskim sustavima. Dobiveni rezultati ispitivanja sa stvarnim podacima Hrvatskog kontrolnog područja pokazuju znatne uštede u troškovima pomoćnih usluga i uočljiv utjecaj različitih odstupanja proizvodnje od plana svake pojedine vjetroelektrane na optimalnu raspodjelu RR.

Ključne riječi: elektroenergetski sustav; evolucijski algoritmi; optimizacija; regulacija frekvencije; regulacijske rezerve; vjetroelektrane

\section{Introduction}

The problem of the efficient management of a power system with a larger share of variable renewable-energy sources (VRES), like solar- or wind-power plants, especially due to their impact on regulating reserve requirements, is frequently encountered in recent scientific sources. However, although there are different solutions that include the impact of VRES generation, many countries are still trying to find the most appropriate one.

In the literature the active participation of windpower plants (WPPs) in system control is frequently encountered, e.g., in [1] and [2] WPPs with a doubly-fed induction generator were applied for the primary frequency and power-reserve control, whereas [3] discusses the inertial support for WPPs. Furthermore, many papers discuss energy-storage systems for reducing the power-system imbalances caused by variable energy sources $[4 \div 7]$. However, in many countries there are no storage possibilities and the owners of WPPs have no interest in participating in LFC because their contracted stimulating prices for generation are higher than the profit from LFC.

The operating impact of wind generation was studied in $[8,9]$, including the issue of grid-balancing requirements. Furthermore, wind power has to be incorporated into the process of operation and reserve planning, since it varies over different time scales (day, hour, minute). The report [10] concludes that the impact of wind-power variability is relatively small in the regulation time scale (minutes), greater during the loadfollowing time scale (minutes to hours), and more significant for the unit commitment/scheduling time scale (day). It was also concluded that efficient wind-power forecasting can help to mitigate the impact of WPPs on the system's operation and costs, but only if used appropriately. A review of studies about WPP integration in the power systems of different countries was given in [11], with a focus on power-system modelling methods and different ways of collecting the data and estimating the regulating and balancing reserve requirements. In $[12 \div 15]$ the authors discuss different methods for calculating the operating reserve by considering windpower forecasts. In [16], the static and dynamic methods were discussed for sizing the regulating reserve (RR) due to increased wind power, and in [17] a newly developed dynamic probabilistic method is described and compared with the static probabilistic method (used in Germany). The report [18] describes a tool developed to define the required operating reserve using the data directly from the wind-power forecast system.

Although the authors in [19] have proposed a similar approach as in this study for the dynamic sizing of the operating reserve, with modifications on an hourly basis, the method employed is different. Both studies consider the wind-power generation forecasts for the next hour, but in [19] the forecasting error is calculated on the basis of statistical data, while this paper proposes a calculation on the basis of errors in the previous hour. Furthermore, the authors in [19] propose a decentralized approach to the generation units' scheduling on market principles, while this paper presents a centralized scheduling of the optimized distribution according to the criterion of minimum power losses (primarily depending on the various errors of different WPPs or WPP groups, tested 
by assuming equal consumption errors across the network).

According to [20, 21], transmission system operators (TSOs) should determine the required RR based on historical data using a defined deterministic or probabilistic method. However, even when considering wind power, such approaches may exclude large changes and tend to underestimate the RR [11]. Therefore, instead of using historical data $[12 \div 19]$, the actual data from the information system in the dispatch centre can be applied for the daily and hourly forecasts of wind-power generation and load demands [22, 23].

This paper is organized as follows. First, a general description of the proposed approach is given. In the next section the method for computing the required regulating power is described, as well as the approach for the RR distribution and transmission-loss minimization using differential evolution (DE), a stochastic search algorithm

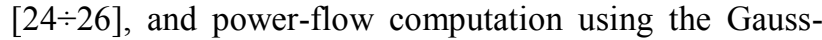
Seidel (GS) iterative method. The testing of the proposed approach is presented in the next section for the Croatian (HR) control area, which already has more than $10 \%$ of installed power from WPPs. Furthermore, the HR area has no energy-storage units, limited RR capabilities, and an intention to double the installed power from WPPs. The following section presents the testing results that confirm the substantial savings in RR costs, as well as a minor reduction in the transmission losses. Finally, the discussion and conclusion are presented.

\section{General description of the proposed approach}

Fig. 1 shows the schematic chart of the proposed approach that can be used for RR distribution according to the minimum transmission losses. The highlighted steps are expanded upon in this study.

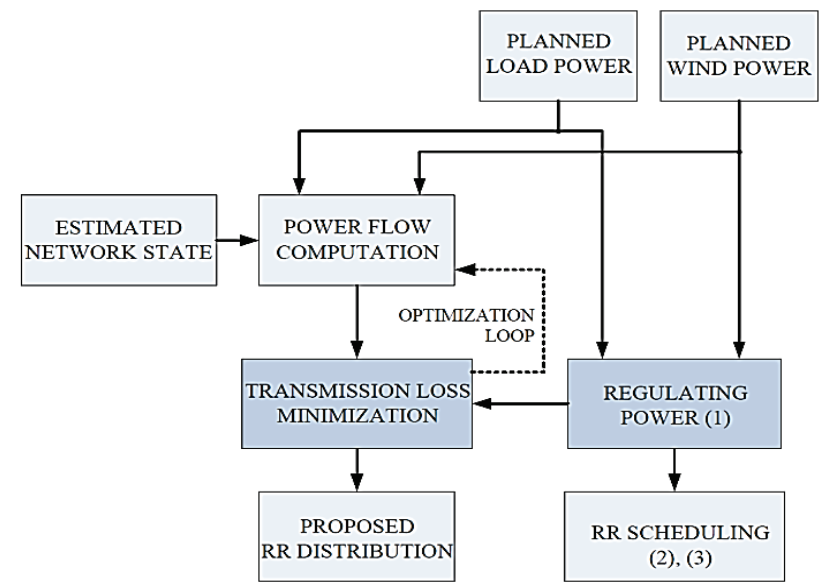

Figure 1 Schematic chart of the proposed approach

The description of each step from Fig. 1 is given as follows:

- Planned load power: Based on statistical data from previous years (considering the day in the week/holiday) for the following hours.

- Planned wind power: Based on meteorological data for the individual WPP or WPP group for the following hours, but with continuous monitoring and correction in the case of larger changes.

- Estimated network state: The data captured from the information system in the dispatch centre, i.e., power plants and transmission lines in operation, generation and consumption in every node, etc.

- Regulating power Eq. (1): Based on the planned load and wind power and on their variations (differences between the planned and actual values) in previous hours.

- $\quad$ RR scheduling Eq. (2), Eq. (3): The schedule with the amount of positive and negative RR for the following hours.

- Power flow computation: Using the GS method with a reactive power correction to retain nodal voltages within defined limits.

- Transmission loss minimization: Optimal distribution of the regulating power based on DE using the criterion of minimal transmission losses.

- Proposed RR distribution: Additionally to be checked by economic criteria and incorporated in a real plan for the following hours as much as possible.

\section{RR distribution based on transmission-loss minimization}

The proposed approach for RR distribution is based on a calculation of the regulating power, i.e., the required active power for LFC. The obtained RR is distributed to the regulating power plants (PPs) based on the criterion of minimal transmission losses. Therefore, the optimization procedure is applied using DE in combination with the power-flow computation using the GS iterative method.

\subsection{Regulating power and RR scheduling}

Regulating power for the next hour $(h)$ has to be available to cover the difference between the planned generation and the actual consumption. In the systems with a large share of VRES, realized generation will vary from plan, as well as the load. Hence, these variations should be assessed and the correction of the day-ahead planned schedules by the known variations from the previous hour is here proposed.

The amount of required regulating power is determined for each successive hour $h$ as

$$
P_{R E G}(h)=\left(P_{W P P}(h)-\sum_{i=1}^{M} k_{W P P i}(H) P_{W P P i}(h)\right)-P_{L}(h)\left(1-k_{L}(H)\right)(1)
$$

where $P_{W P P}$ is the planned power of all the WPPs, $P_{W P P i}$ is the planned power of the $i^{\text {th }}$ WPP or WPP group, and $P_{L}$ is the total load power. The coefficients $k_{W P P i}$ and $k_{L}$ are given for the previous $H^{\text {th }}$ hour and are defined as the ratio of the actual and planned powers of the $i^{\text {th }}$ WPP or WPP group and the ratio of the actual and planned load power, respectively.

Furthermore, Eq. (1) is used to determine the RR, separately in the positive and negative directions. The RR should cover the forecast errors and the sub-hourly variations in the actual wind and load powers. Therefore, an increase of the reserve is advisable during sudden changes, especially when the derivative of $P_{R E G}$ changes its sign. At the same time, it is necessary to ensure at least the minimum reserves in the opposite direction. Thus, the positive and negative RR are, respectively, determined as 


$$
\begin{aligned}
& P_{R R+}(h)= \begin{cases}a_{1} \cdot P_{R E G}(h)+D_{\text {corr }}(h) & \text { if } \quad P_{R E G}(h)>0 \\
a_{2} \cdot P_{\min p}+a_{3} \cdot|d(h)| & \text { if }\left(P_{R E G}(h) \leq 0\right) \operatorname{AND}\left((d(h)>0) \operatorname{OR}(d(H)>0) \operatorname{OR}\left(P_{R E G}(H)>0\right)\right) \\
P_{\min p} & \text { else }\end{cases} \\
& P_{R R-}(h)= \begin{cases}a_{1} \cdot P_{R E G}(h)-D_{\text {corr }}(h) & \text { if } P_{R E G}(h)<0 \\
a_{2} \cdot P_{\min n}-a_{3} \cdot|d(h)| & \text { if }\left(P_{R E G}(h) \geq 0\right) \operatorname{AND}\left((d(h)<0) \operatorname{OR}(d(H)<0) \operatorname{OR}\left(P_{R E G}(H)<0\right)\right) \\
P_{\min n} & \text { else }\end{cases}
\end{aligned}
$$

where $a_{1}, a_{2}$ and $a_{3}$ are safety factors, $P_{\min p}$ and $P_{\min n}$ denote the minimum positive and negative reserves, respectively. The additional correction term $D_{\text {corr }}(h)$ that covers for sudden changes in $P_{R E G}$ is determined by Eq. (4), whereas the derivative $d(h)$, indicating the trend of the time series, is determined numerically by Eq. (5).

$$
\begin{aligned}
& D_{\text {corr }}(h)=\left\{\begin{array}{lll}
b_{1}|d(h)| & \text { if } & d(h) d(H)<0 \\
b_{2}|d(h)| & \text { if } & (d(h) d(H)>0) \operatorname{AND}(|d(h)|<|d(H)|) \\
b_{3}|d(h)| & \text { if } & (d(h) d(H)>0) \operatorname{AND}(|d(h)|>|d(H)|) \\
P_{\min p} & \text { else }
\end{array}\right. \\
& d(h)=\frac{3 \cdot P_{R E G}(h)-4 \cdot P_{R E G}(h-1)+P_{R E G}(h-2)}{2}
\end{aligned}
$$

The factors $a_{1}, a_{2}, b_{1}, b_{2}$ should be between 1 and 1,5, whereas $a_{3}, b_{3}$ can be between 0,5 and 1 , depending on the system specifics and the quality of the forecasts. They should be determined empirically according to historical data for a particular power system. Furthermore, the minimum amount of reserves $P_{\min p}$ and $P_{\min n}$ should cover at least for the expected value of the net-forecast error, i.e., the wind-forecast error reduced by the load-forecast error. A practical choice is given by the 70th percentile for the $P_{\min p}$ and the $30^{\text {th }}$ percentile for the $P_{\min n}$.

Scheduling by Eq. (2) and Eq. (3), instead of a superficially or flat-rate determined range, can ensure enough RR in the positive and negative directions for safe operation, while reducing the costs for holding the units that are ready for regulation.

\subsection{Power-Flow Computation}

Gauss-Seidel (GS) and Newton-Raphson (NR) are iterative numerical methods that are the most commonly used for AC power-flow computations [27]. Due to large variations in nodal voltages, the GS method is the more suitable one, although the NR method is more frequently encountered [28].

The voltage phasor for the $p^{\text {th }}$ node is determined for the $k^{\text {th }}$ iteration by

$$
\underline{U}_{p}(k)=\frac{\underline{K}_{p p}}{\underline{U}_{p}^{*}(k-1)}-\sum_{i=1}^{p-1} \underline{U}_{i}(k) \underline{K}_{p i}-\sum_{i=p+1}^{N} \underline{U}_{i}(k-1) \underline{K}_{p i}
$$

where $N$ is the number of all the independent nodes, $(\bullet)^{*}$ denotes the complex conjugate, while the constant $K_{p i}$ is given by the ratio of the admittances $\left(Y_{p i} / Y_{p p}\right) . K_{p p}$ is given by the ratio of the nodal apparent power and the admittance $\left(S_{p}^{*} / Y_{p p}\right)$, taking into account the load power, the power from all the PPs, including regulating PPs and WPPs, as well as the scheduled interchange power on the area's tie-lines. In order to maintain the nodal voltages within the prescribed limits the reactive power is corrected, which for the $p^{\text {th }}$ node and $k^{\text {th }}$ iteration is determined by

$$
Q_{p}(k)=\operatorname{Im}\left\{\left(\underline{U}_{p}(k)\right)^{2} \underline{Y}_{p p}+\underline{U}_{p}^{*}(k)+\sum_{i=1}^{p-1} \underline{U}_{i}(k) \underline{Y}_{p i}+\sum_{i=p+1}^{N} \underline{U}_{i}(k) \underline{Y}_{p i}\right\}(7)
$$

When $Q_{p}(k)<Q_{p \min }$ then $K_{p p}$ is recalculated using $Q_{p \min }$, whereas when $Q_{p}(k)>Q_{p \max }$, then $Q_{p \max }$ is used instead. Note that the reactive power correction is only applied to nodes with voltage regulation. The computation is repeated for all the nodes and with a satisfactory accuracy, or to a given maximum number of iterations.

The power flow through a transmission line, e.g., between the nodes $p$ and $q$, is determined by

$$
\underline{S}_{p q}=\underline{U}_{p} \underline{I}_{p q}^{*}=\underline{U}_{p}\left(\left(\underline{U}_{q}-\underline{U}_{p}\right) \underline{Y}_{p q}+\underline{U}_{p} \cdot \underline{B}_{p q}\right)^{*}
$$

where $I_{p q}$ is the current phasor and $B_{p q}$ denotes the line susceptance. The transmission losses on the line $p-q$ are determined as $\operatorname{Re}\left\{S_{p q}-S_{q p}\right\}$, whereas the total transmission losses are calculated as the sum of the losses on all the lines.

\subsection{Transmission-loss minimization and RR distribution}

The procedure for transmission-loss minimization and RR distribution is briefly described in the following steps:

- Step 1) Initial transmission losses are computed for a random distribution of $P_{R E G}$ using the GS method.

- Step 2) The new distribution of $P_{R E G}$ is determined by $\mathrm{DE}$ for all the regulating PPs ready for the Automatic Generation Control (AGC).

- Step 3) For the $j^{\text {th }}$ regulating PP constraints are checked. When $P_{\max }<P_{R E G j}<P_{\text {min }}$, then $P_{R E G j}$ is redistributed to the other PPs.

- Step 4) Transmission losses are computed for the current distribution of $P_{R E G}$ using the GS method. The procedure continues with Step 2) until a minimum transmission-loss variation or a maximum number of evolutionary iterations are achieved.

- Step 5) For the optimal distribution of $P_{R E G}$ the RR are determined using Eq. (2) and Eq. (3). 


\section{A case study}

The proposed approach for $\mathrm{RR}$ distribution and transmission-loss minimization was tested for the HR control area, which is a part of the synchronous area of continental Europe (CE). The complete Croatian transmission system as presented in [29] was modelled for the power-flow computation, considering all the PPs and the $110-\mathrm{kV}, 220-\mathrm{kV}$ and $400-\mathrm{kV}$ transmission lines with a total of 171 nodes. Fig. 2 shows only the $400-\mathrm{kV}$ transmission lines (TL), along with all the WPPs and WPP groups in operation (a total installed power of 420 MW [30]), and the regulating hydro-power plants (HPPs). Only HPP1-HPP3 are incorporated in the AGC system; their data are given in Tab. 1, whereas HPP4-HPP8 can be used for LFC only manually, after a phone call from the national dispatch centre (NDC).

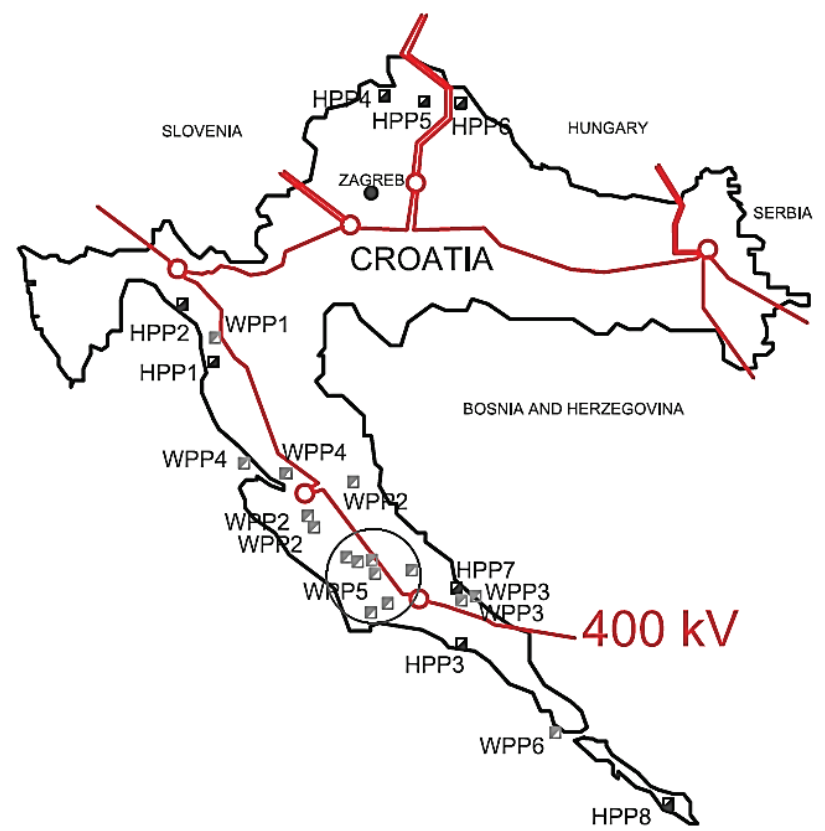

Figure 2 The Croatian $400 \mathrm{kV}$ TL and the locations of the WPPs (gray) and HPPs (black)

Table 1 Data of regulating HPPs

\begin{tabular}{|c|c|c|}
\hline HPP No. & $\begin{array}{c}\text { Installed power } \\
\text { (MW) }\end{array}$ & $\begin{array}{c}\text { Regulating range } \\
\text { (MW) }\end{array}$ \\
\hline 1 & 216 & 70 \\
\hline 2 & 90 & 90 \\
\hline 3 & 522 & 120 \\
\hline
\end{tabular}

The closeness of the geographical areas with the installed WPPs and the very stimulating prices for their generation lead to a considerable correlation between the required $R R$ and the amount of installed power from the WPPs. However, the control of the HR area (including LFC) is performed by the NDC, which was recently modernized by applying Wide Area Monitoring Systems (WAMS) and a state estimation that uses WAMS-based phasor measurements [31]. The proposed approach for the optimal RR distribution, which is based on static computation, can use the WAMS-based data.

\subsection{Current approach for RR scheduling}

A deterministic approach is used that does not account for the fluctuations in $P_{W P P}[20]$. The slower part of RR (tertiary reserve) is $80 \mathrm{MW}$ during the whole year, and the faster part (secondary reserve) of $R R$ is determined as

$$
P_{R R}=\sqrt{a \cdot L_{\max }+b^{2}}-b
$$

where $L_{\max }$ is the maximum anticipated load, which is between 1172,5 MW and 2812,5 MW for the HR area, whereas the constants $a=10 \mathrm{MW}$ and $b=150 \mathrm{MW}$ are empirically determined for the entire synchronous area of CE. The obtained RR is the same in both directions. The recommended minimum of secondary RR for the HR area is between $35 \mathrm{MW}$ and $75 \mathrm{MW}$, whereas the current daily secondary RR schedule is shown in Fig. 3.

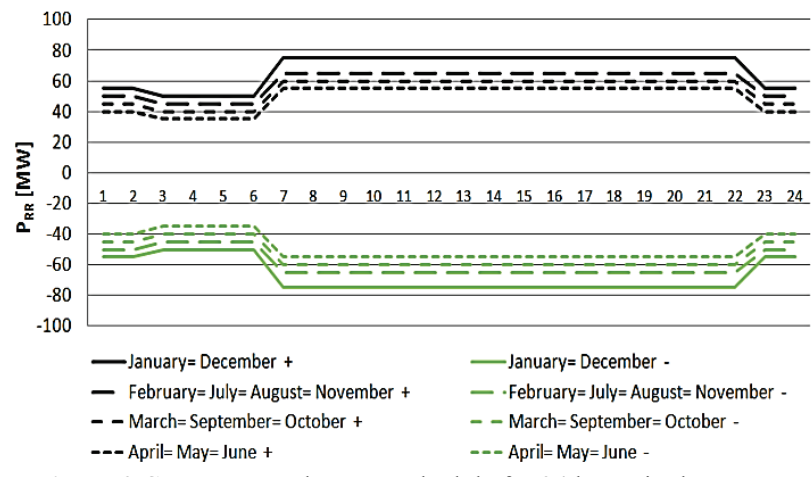

Figure 3 Current secondary RR schedule for 24 hours in the HR area

\subsection{Wind and Load Power}

The WPPs in Croatia are divided into six groups according to their geographical location (Fig. 2). The real wind power of groups WPP1-WPP3 was obtained in $\mathrm{MWh} / \mathrm{h}$ from the owners, whereas the generation output of groups WPP4-WPP6 was unknown. Since all the wind power was obtained from the TSO, the difference was distributed among WPP4, WPP5 and WPP6, according to their installed power and the ratio of generation of the WPPs nearby. The real total load power (the data was also obtained from the TSO) was evenly divided over all the nodes in the transmission system. Twelve representative days in 2015, as listed in Tab. 2, were selected for testing the proposed approach, taking into account working days, weekends and holidays during the spring, summer, autumn and winter.

Table 2 The selected days for testing the proposed approach

\begin{tabular}{|l|l|l|}
\hline \multicolumn{1}{|c|}{ date in 2015} & $\begin{array}{c}\text { week in the month / } \\
\text { day in the week }\end{array}$ & \multicolumn{1}{c|}{ type of the day } \\
\hline January 11 & Second Sunday & Weekend \\
\hline January 15 & Third Wednesday & Working day \\
\hline March 8 & Second Sunday & Weekend \\
\hline April 15 & Third Wednesday & Working day \\
\hline April 26 & Fourth Sunday & Weekend \\
\hline July 15 & Third Wednesday & Working day \\
\hline July 19 & Third Sunday & Weekend \\
\hline August 15 & Third Saturday & Weekend /Holiday \\
\hline September 7 & First Monday & Working day \\
\hline October 18 & Third Sunday & Weekend \\
\hline October 21 & Fourth Wednesday & Working day \\
\hline December 24 & Fourth Thursday & Week/Holiday \\
\hline
\end{tabular}


A histogram for the wind-power forecast error (WPFE) from the data for the selected days is presented in Fig. 4. The differences (Fig. 4a) between the hourly planned (a day-ahead forecasts) and realized generation in (h) calculated with Eq. (10) are more dispersed (less accurate) than the differences (Fig. 4b) between the planned values (a day-ahead forecasts) corrected with the previous-hour error $\left(k_{W P P}(H)\right)$ and the realized generation in $(h)$ calculated with Eq. (11). This is the main reason for proposing such correcting coefficients in this approach.

$$
\begin{aligned}
& \Delta P_{W}=P_{W P P}(h) \cdot\left(1-k_{W P P \Sigma}(h)\right) \\
& \Delta P_{W_{\text {corr }}}=P_{W P P}(h) \cdot\left(k_{W P P \Sigma}(H)-k_{W P P \Sigma}(h)\right)
\end{aligned}
$$
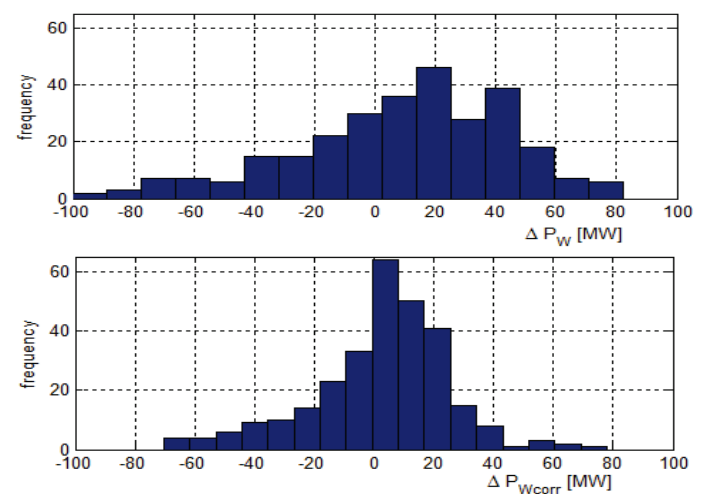

Figure 4 Histogram for WPFE (a) for day-ahead forecast, (b) with previous-hour correction

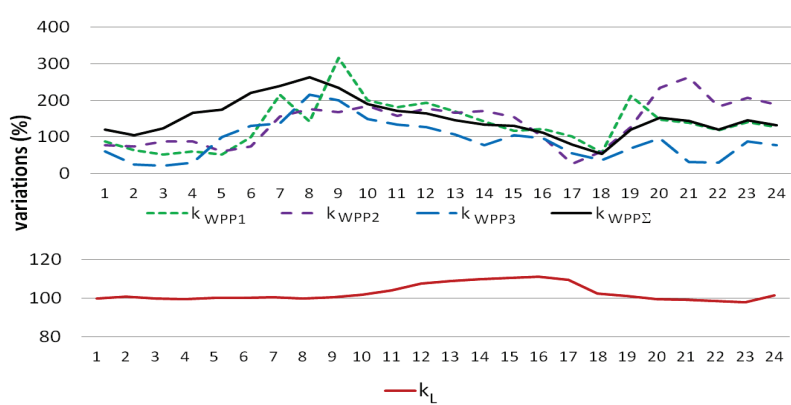

Figure 5 The Variation of planned wind and load power, for January 11, 2015

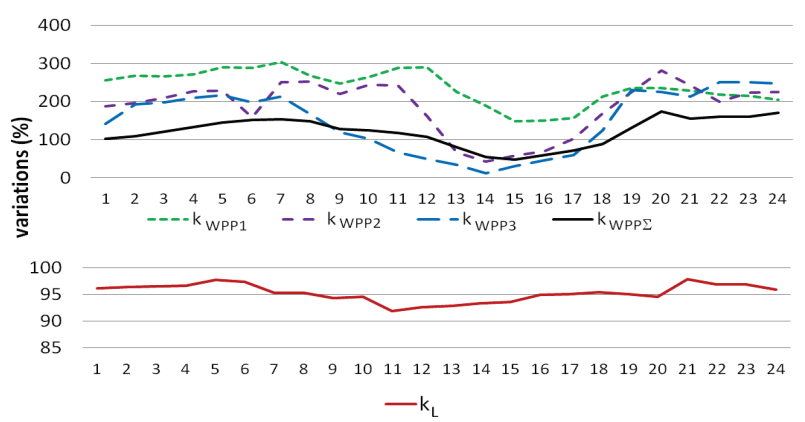

Figure 6 The Variation of planned wind and load power, for September 7,2015

Fig. 5 and 6 show the daily variations of the coefficients $k_{W P P i}$ for WPP1-WPP3, for all the WPPs $\left(k_{W P P \Sigma}\right)$ and for the load $\left(k_{L}\right)$ for the two most representative days, i.e., January 11, and September 7, 2015. Large amounts of positive regulating power are expected when there is a coincidence between the WPP generation deficit (less than planned) and the consumption surplus (more than planned), as shown in Fig. 5 (hours $16 \div 18$ ). Furthermore, when the WPP generation surplus and consumption deficit coincide, then large amounts of negative regulating power are expected, as shown in Fig. 5 (hours $20 \div 23$ ) and Fig. 6 (hours $2 \div 12$ and $19 \div 24$ ).

Generally, no particular local correlation could be found between the total wind-power and the load-power variations. Moreover, when considering all the discussed days, then the overall correlation between the wind- and load-power variations was less than 0,1 .

\section{Results \\ 5.1 Optimal Regulating Power Distribution}

Considering the available wind-power data (only the planned power of all the WPPs, not for each $i^{\text {th }}$ WPP) and the daily-load power curve, the calculation of the regulating power Eq. (1) was adapted as

$$
P_{R E G}(h)=P_{W P P}(h)\left(1-\sum_{i=1}^{6} k_{W P P i}(H) \cdot \frac{P_{i}}{P_{W}}\right)-P_{L}(h)\left(1-k_{L}(H)\right)
$$

where $P_{i}$ is the installed wind power of the $i^{\text {th }}$ WPP group, $P_{W}$ is the installed wind power of all the WPPs and the coefficients $k_{W P P i}$ and $k_{L}$ were given for the previous hour $(H=h-1)$. The factors in Eq. (2) $\div$ Eq. (5) were determined by graphical analysis of multiple time series and set as $a_{1}=1,3 ; a_{2}=1,2 ; a_{3}=0,7 ; b_{1}=1,2 ; b_{2}=1,4$ and $b_{3}=0,5$. The minimum values for the positive and negative reserves were obtained as $P_{\min p}=+42 \mathrm{MW}$ and $P_{\min n}=-25 \mathrm{MW}$ through the convolution of the probability distribution functions of hourly wind- and negative-load-forecast errors, using a versatile probability distribution model [32] for the data during the entire year.
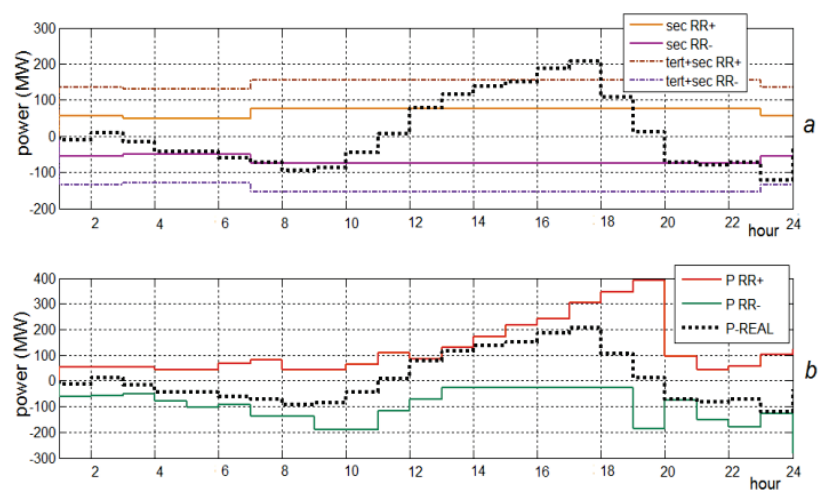

Figure 7 RR schedule and the really needed reg. power for January 11, 2015 (a) by current approach, (b) by proposed approach

Figs. 7 and 8 show the positive and negative RR schedules for both representative days as determined using Eq. (12) and then Eq. (2) and Eq. (3), compared with the really needed RR calculated with known values for the planned and realized generation and consumption in $h$ hour. The obtained results (Figs. $7 \mathrm{~b}$ and 8b) correspond to the wind and load power variations (Figs. 5 and 6). A comparison with the current RR schedule (Fig. 7a and 8a) indicates that the proposed approach can reduce the unnecessary positive and negative $R R$, which are very costly, as well as an insufficient RR that requires the activation of additional reserves. 

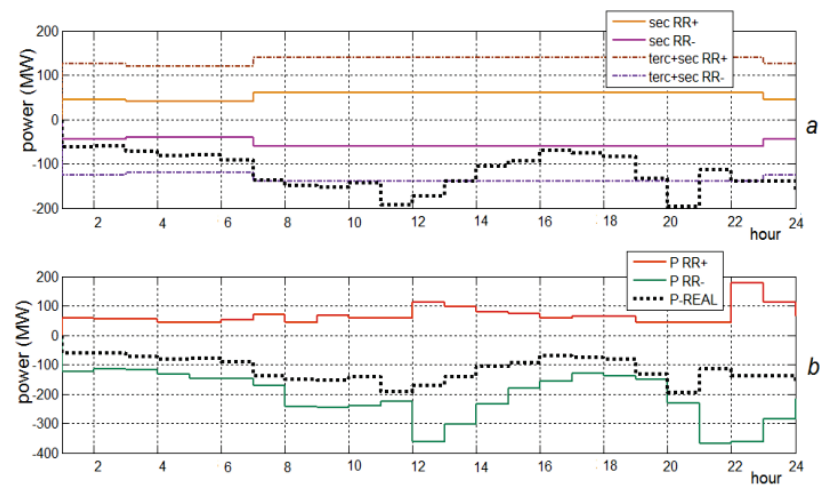

Figure 8 RR schedule and the really needed reg. power for September 7, 2015 (a) by current approach, (b) by proposed approach

The distribution of the regulating power among all three HPPs was optimized using the DE strategy best/1/exp [25], where the DE parameters were set, as given in Tab. 3. The obtained results for both representative days are shown in Figs. $9 \mathrm{a}$ and $9 \mathrm{~b}$. In the cases when extremely large amounts of positive or negative regulating power were needed, the optimal distribution cannot be provided due to a violation of the HPP constraints. However, in all other situations, the distribution of the regulating power minimizes the transmission losses.

Table 3 The DE parameters

\begin{tabular}{|l|c|}
\hline Number of parameters (HPPs) & 3 \\
\hline Population size & 10 \\
\hline Step size & 0,7 \\
\hline Crossover probability constant & 0,5 \\
\hline Number of maximum iterations & 35 \\
\hline
\end{tabular}

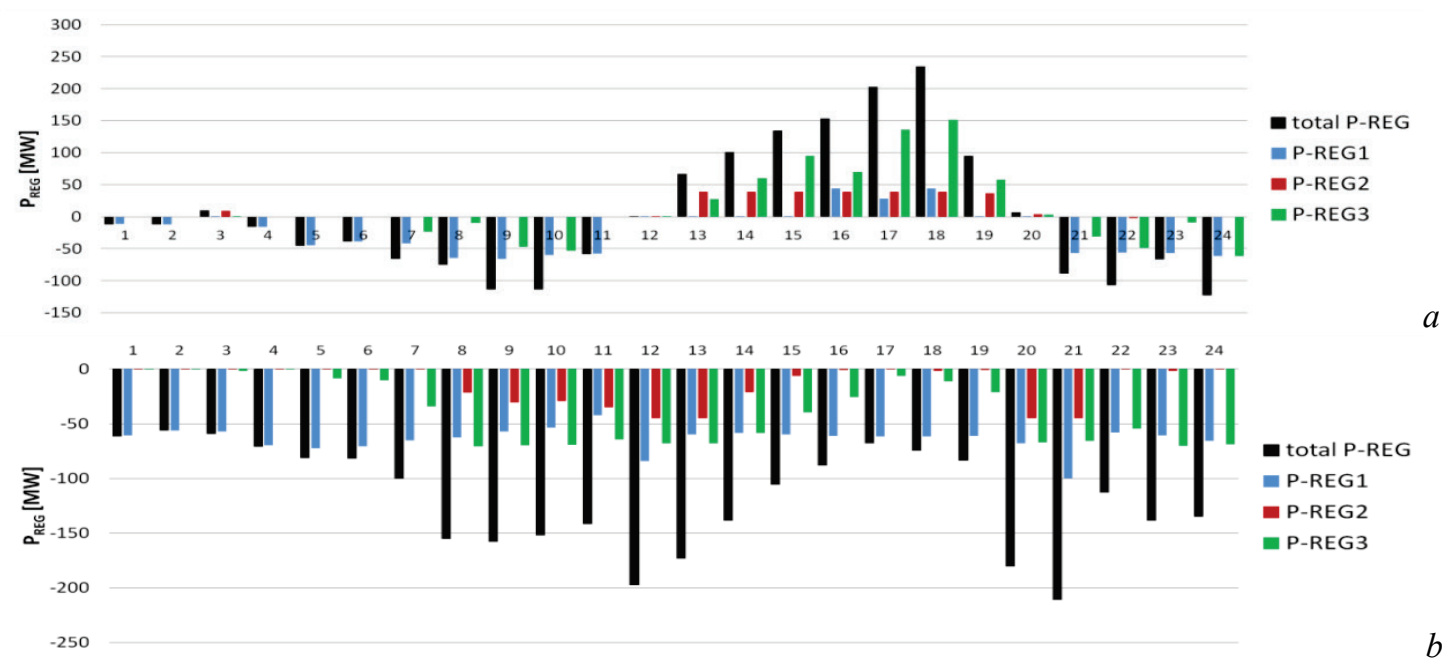

Figure 9 Optimal distribution of $P_{R E G}$, (a) for January 11, 2015, (b) for September 7, 2015

\subsection{Transmission Losses}

In order to evaluate the transmission losses obtained using the proposed approach (optimal RR distribution), more computations were performed, considering four typical scenarios currently used in the HR area, i.e.:

- Scenario 1) HPP2 has priority and only if more power is needed, then HPP1 and after it HPP3 will participate in the LFC.

- Scenario 2) HPP3 has priority and only if more power is needed, then HPP2 and after it HPP1 will participate in the LFC.

- Scenario 3) HPP1 has priority in the negative direction, HPP3 has priority in the positive direction, and if more power is needed, the other HPPs will participate in the LFC.

- Scenario 4) Only HPP2 is ready during the night, and HPP1 has priority in the negative direction, HPP3 has priority in the positive direction during the day, and if more power is needed, the other HPPs will participate in the LFC.

Fig. 10 shows a comparison of the total daily transmission losses between the proposed approach and all four scenarios for all 12 selected days. The obtained results confirm that the total daily transmission losses vary depending on which HPP will provide the necessary regulating power. Considering the close geographical position between the WPPs and the regulating HPPs (Fig. 2), lower transmission losses will be achieved with an activation of the regulating HPP that is closer to the WPP with the highest wind-power variation.

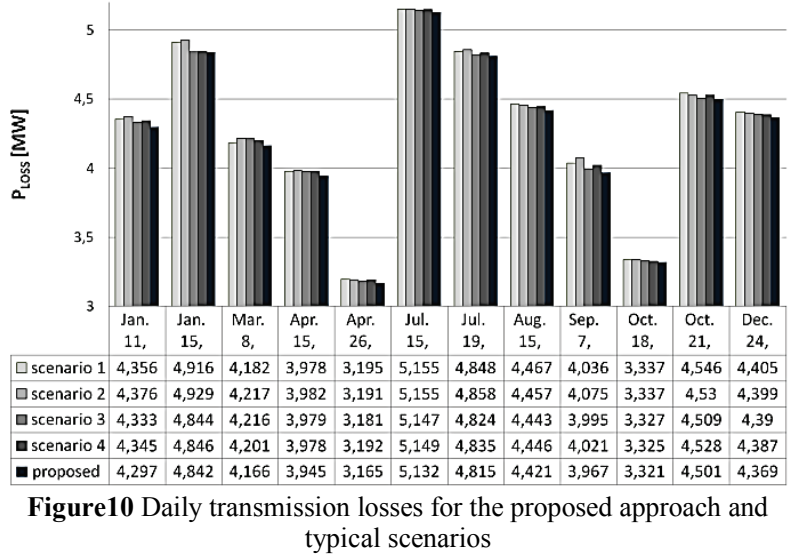

The distribution obtained with the proposed approach gives the optimal solution when considering the planned wind power and anticipated forecast errors, which can lead to a reduction of the transmission losses. The 
percentage decrease of the transmission losses, when compared with the discussed typical scenarios, is between 1 and $2 \%$. However, with a larger share of generation from the WPPs and with more dispersed locations of the regulating PPs a considerable decrease in the transmission losses could be obtained.

\subsection{Economic Benefits}

Tab. 4 shows the results for the daily sum of $R R$ obtained with the proposed and the current approaches, as well as the daily cost for RR when using the agreed price of $13,75 € / \mathrm{MW}$ for the secondary and $6,39 € / \mathrm{MW}$ for the tertiary reserve. The difference in the RR costs obtained using both approaches indicates a total saving of $21,2 \%$ for all 12 selected days. The secondary reserve price of $13,75 € / \mathrm{MW}$ was used for the proposed approach, i.e., assuming all the RR units to be fast. In practice, a part of the reserve can be slow (tertiary), and the savings would be even higher. Furthermore, for almost all the discussed days, the sum of the hourly amounts of the RR cost was significantly smaller than with the current approach. Only on September 7 was the cost using the proposed approach significantly higher, when extremely large amounts of negative RR were needed.

Table 4 Comparison of daily sum of $P_{R R}$ and RR cost between the proposed and current approach (secondary+tertiary)

\begin{tabular}{|l|r|r|r|r|r|}
\hline $\begin{array}{c}\text { date in } \\
2015\end{array}$ & $\begin{array}{c}P_{R R}(\mathrm{MW}) \\
\text { (proposed) }\end{array}$ & $\begin{array}{c}P_{R R}(\mathrm{MW}) \\
\text { (current) }\end{array}$ & $\begin{array}{c}\text { RR cost } \\
(€) \\
\text { (proposed) }\end{array}$ & $\begin{array}{c}\text { RR cost } \\
(€) \\
(\text { current) }\end{array}$ & $\begin{array}{c}\text { diff. in } \\
\text { RR cost } \\
(€)\end{array}$ \\
\hline Jan. 11 & 5403 & 7080 & 74293 & 69088 & 5206 \\
\hline Jan. 15 & 3834 & 7080 & 52712 & 69088 & -16376 \\
\hline Mar. 8 & 3568 & 6760 & 49065 & 64688 & -15623 \\
\hline Apr. 15 & 3729 & 6640 & 51280 & 63038 & -11757 \\
\hline Apr. 26 & 3243 & 6640 & 44586 & 63038 & -18451 \\
\hline Jul. 15 & 2960 & 6880 & 40703 & 66338 & -25634 \\
\hline Jul. 19 & 3314 & 6880 & 45574 & 66338 & -20764 \\
\hline Aug. 15 & 3493 & 6880 & 48031 & 66338 & -18307 \\
\hline Sep. 7 & 6665 & 6760 & 91650 & 64688 & 26962 \\
\hline Oct. 18 & 2685 & 6760 & 36917 & 64688 & -27770 \\
\hline Oct. 21 & 3116 & 6760 & 42840 & 64688 & -21848 \\
\hline Dec. 24 & 3307 & 7080 & 45475 & 69088 & -23613 \\
\hline sum & 45318 & 82200 & 623126 & 791101 & -167975 \\
\hline
\end{tabular}

\section{Discussion}

TSOs as public companies have an interest in reducing transmission losses, when possible, due to environmental concerns and information transparency, and other public-interest issues. Furthermore, they already have all the necessary data in the information system needed to implement the proposed approach. This approach could help the TSOs to decide which regulating $\mathrm{PP}$ would be better to require the regulating power in order to minimize the transmission losses. Moreover, the proposed approach could also reduce the RR costs. The ancillary-services provider can accept the proposed RR schedule to the maximum extent that the other conditions allow (hydrological, environmental, economic, etc.), while the different schedule has no negative impact on the regulating units themselves.

By switching to a market-oriented power-system operation, all the subjects responsible for imbalances will have to participate in balancing costs. However, WPPs in Croatia are currently not operating under market conditions. They have very stimulating contracted prices, and thus a direct financial interest in generating the maximum possible amount of active power all the time. On the other hand, the TSO has to pay the WPP owners for their generation, as well as for the negative RR to annul their over-generation if the wind is more favourable than expected. Therefore, it would be reasonable to prevent WPP generation that is higher than planned, e.g., over 10 or $20 \%$ higher (currently the generation surplus of WPPs in the HR area can be as much as $300 \%$, as shown in Fig. 5). This would stimulate WPP owners (or balance group coordinators in the future) to forecast their generation in a more accurate way, re-plan the wind power a few times a day, if necessary, and consequently stay within the foreseen limits that ensure a secure system operation.

\section{Conclusion}

The main objectives of this research were to improve the planning of the required regulating power in control areas with a large share of wind power and to indicate the impact of RR distribution on the transmission losses. Both objectives were achieved for the discussed HR control area, using real data from representative days in 2015. The obtained savings in RR costs for the selected 12 days were substantial, i.e., $21,2 \%$. The results obtained for the transmission-loss minimization were not so promising, since up to $2 \%$ of loss reduction was achieved, which is due to the relatively small share of the WPP generation (10\%) and a close geographical position between the WPPs and the regulating HPPs. Also, such a small difference compared with the often-used scenarios can indicate a good and experienced practice in current reserve scheduling. It is certainly worth investigating further.

The proposed approach has the simplicity of deterministic methods, while considering load- and windpower forecasts, to ensure easy implementation in the systems with insufficient historical data for advanced probabilistic methods. Furthermore, the system conditions are considered, but without intensive and continuous computations that can be performed more times a day. Moreover, the proposed approach can be further improved by adding the economic criteria before the final schedule for the optimal distribution is made.

\section{References}

[1] Žertek, A.; Verbič, G.; Pantoš, M. A novel strategy for variable-speed wind turbines' participation in primary frequency control. // IEEE transactions on sustainable energy. 3, 4(2012), pp. 791-799. https://doi.org/10.1109/TSTE.2012.2199773

[2] Žertek, A.; Verbič, G.; Pantoš, M. Optimised control approach for frequency-control contribution of variable speed wind turbines. // IET renewable power generation. 6, 1(2012), pp. 17-23. https://doi.org/10.1049/iet-rpg.2010.0233

[3] Bećirović, E.; Osmić, J.;Kušljugić, M. et al. Analysis and synthesis of model reference controller for variable speed wind generators inertial support. // Journal of electrical engineering. 66, (2015), pp. 3-10. https://doi.org/10.1515/jee-2015-0001 
[4] Vlot, M. C.; Knigge, J. D.; HanSlootweg, J. G. Economical Regulation Power Through Load Shifting With Smart Energy Appliances. // IEEE transactions on smart grid. 4, 3(2013), pp. 1705-1712. https://doi.org/10.1109/TSG.2013.2257889

[5] Lee, J.; Kim J. H.; Joo, S. K. Stochastic Method for the Operation of a Power System With Wind Generators and Superconducting Magnetic Energy Storages (SMESs). // IEEE transactions on applied superconductivity. 21, 3(2011), pp. 2144-2148 https://doi.org/10.1109/TASC.2010.2096491

[6] Pillai, J. R.; Bak-Jensen, B. Integration of Vehicle-to-Grid in the Western Danish Power System. // IEEE transactions on sustainable energy. 1, 1(2011), pp. 12-19.

[7] Xie, P. P.; Li, Y. H.; Zhu, L. et al. Supplementary automatic generation control using controllable energy storage in electric vehicle battery swapping stations. // IET generation transmission \& distribution. 10, 4(2016), pp. 1107-1116. https://doi.org/10.1049/iet-gtd.2015.0167

[8] Smith, J. C.; Milligan, M.; DeMeo, E. et al. Utility Wind Integration and Operating Impact State of the Art. // IEEE transactions on power systems. 22, 3(2007), pp. 900-908. https://doi.org/10.1109/TPWRS.2007.901598

[9] Makarov, Y. V.; Loutan, C.; Jian, M.et al. Operational Impacts of Wind Generation on California Power Systems. // IEEE transactions on power systems. 24, 2(2009), pp. 1039-1050. https://doi.org/10.1109/TPWRS.2009.2016364

[10] Parsons, B.; Milligan, M.; Smith, J. C. et al. Grid Impacts of Wind Power Variability: Recent Assessments from a Variety of Utilities in the United States. // Conference Paper NREL/CP-500-39955 / Washington, D.C., 2006, pp. 1-13.

[11] Dowds, J.; Hines, P.; Ryan, T. et al. A review of large-scale wind integration studies. // Renewable and Sustainable Energy Reviews. 49, (2015), pp. 768-794. https://doi.org/10.1016/j.rser.2015.04.134

[12] Menemenlis, N.; Huneault, M.; Robitaille, A. Computation of Dynamic Operating Balancing Reserve for Wind Power Integration for the Time-Horizon 1-48 Hours. // IEEE transactions on sustainable energy. 3, 4(2012), pp. 692-702. https://doi.org/10.1109/TSTE.2011.2181878

[13] Hirth, L.; Ziegenhagen, I. Balancing power and variable renewable: Three links. // Renewable and Sustainable Energy Reviews. 50, (2015), pp. 1035-1050. https://doi.org/10.1016/j.rser.2015.04.180

[14] Rahmann, C.; Heinemann, A.; Torres, R. Quantifying operating reserves with wind power: towards probabilisticdynamic approaches. // IET Generation, Transmission \& Distribution. 10, 2(2016), pp. 366-373. https://doi.org/10.1049/iet-gtd.2015.0538

[15] Bruninx, K.; Delarue, E. A Statistical Description of the Error on Wind Power Forecasts for Probabilistic Reserve Sizing. // IEEE transactions on sustainable energy. 5, 3(2014), pp. 995-1002. https://doi.org/10.1109/TSTE.2014.2320193

[16] Holttinen, H.; Milligan, M.; Ella, E. et al. Methodologies to Determine Operating Reserves Due to Increased Wind Power. // IEEE transactions on sustainable energy. 3 4(2012), pp. 713-723. https://doi.org/10.1109/TSTE.2012.2208207

[17] Jost, D.; Speckmann, M.; Sandau, F. et al. A new method for day-ahead sizing of control reserve in Germany under a $100 \%$ renewable energy sources scenario. // Electric Power Systems Research. 119, (2015), pp. 485-491. https://doi.org/10.1016/j.epsr.2014.10.026

[18] Matos, M. A.; Bessa, R. J. Setting the Operating Reserve Using Probabilistic Wind Power Forecasts. // IEEE transactions on power systems. 26, 2(2011), pp. 594-603. https://doi.org/10.1109/TPWRS.2010.2065818
[19] De Vos, K.; Driesen, J. Dynamic operating reserve strategies for wind power integration. // IET Renewable Power Generation. 8, 6(2014), pp. 598-610. https://doi.org/10.1049/iet-rpg.2013.0209

[20] European Network of Transmission System Operators for Electricity, Operation, Network Code on Load-Frequency Control and Reserves, 2013

[21] European Network of Transmission System Operators for Electricity, Operation Handbook-P1, Load Frequency Control and Performance, 2009.

[22] Wind power forecasting curve, http://files.hrote.hr/files/ EKO_BG/FORECAST/WIND/indexOK.html, (22.07.2016)

[23] Daily demand curve, http://www.hops.hr/wps/portal/ $\mathrm{hr} /$ web/hees/dijagram/dnevni, (22.07.2016).

[24] Price, K. V.; Storn, R. M.; Lampinen, J. A. Differential Evolution, Springer, 2005.

[25] Storn, R. On the usage of differential evolution for function optimization, In Biennial Conference of the North American Fuzzy Information Processing Society (NAFIPS 1996), Berkeley, CA, / New York, IEEE, 1996, pp. 519523. https://doi.org/10.1109/NAFIPS.1996.534789

[26] Garrido, R. C.; Štumberger, G.; Voršič, J. Optimizing production of electric energy from renewable sources by differential evolution. // International Conference on Renewable Energies and Power Quality / Sevilla, Spain, 2007, http://www.icrepq.com/icrepq07/242-costa.pdf

[27] Gönen, T. Modern Power System Analysis, Taylor \& Francis Group, New York, 2013, 2nd ed.

[28] Singhal, K. Comparison between Load Flow Analysis in Power System using MATLAB. // International Journal of Scientific \& Engineering Research. 5, 5(2014), pp. 14121419.

[29] The Croatian transmission system 110-220-400 kV scheme, Nov. 2015, htttp:/www.hops.hr/wps/portal/ hr/web/hees/ podaci/shema, (19.07.2016).

[30] Wind power plants in HR control area, http://www.hops.hr/ wps/wcm/connect/b77a8d1b-8c1a-427a-967bf75e $25 \mathrm{bdb} 10 \mathrm{a} /$ Vjetroelektrane $+\mathrm{u}+$ pogonu.pdf?MOD= AJPERES, (19.07.2016).

[31] Skok, S.; Šturlić, I.; Matica, R. Multipurpose open system architecture model of wide area monitoring. // PowerTech Conference, IEEE, / Bucharest, Romania, 2009, pp. 1-6.

[32] Zhang, Z.-S.; Sun, Y.-Z.; Gao, D. W.; Lin, J.; Cheng, L. A Versatile Probability Distribution Model for Wind Power Forecast Errors and Its Application in Economic Dispatch. // IEEE transactions on power systems. 28, 3(2013), pp. 3114-3125. https://doi.org/10.1109/TPWRS.2013.2249596

\section{Authors' addresses}

\section{Dunja Srpak, Lecturer}

Department of Electrical Engineering, University North, 104. Brigade 3, 42000 Varaždin, Croatia dunja.srpak@unin.hr

Boštjan Polajžer PhD, Assoc. Prof.

Faculty of Electrical Engineering and Computer Science, University of Maribor,

Smetanova 17, 2000 Maribor, Slovenia

bostjan.polajzer@um.si 